\title{
Classification of Periodontal Diseases - Old is Gold or New is Bold? A Survey Study in Egypt
}

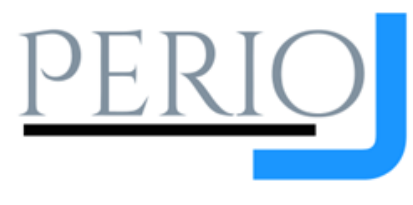

\author{
Marwa M. Hegab, ${ }^{A}$ Maha Abdelkawy ${ }^{B}$ \\ A Department of Oral Medicine and Periodontology, Faculty of \\ Dentistry, Cairo University, Cairo, Egypt. \\ B Department of Oral Medicine and Periodontology, Faculty of \\ Dentistry, Beni-Suef University, Beni-Suef, Egypt.
}

Accepted for publication: June 08, 2020

\begin{abstract}
Background: A consensus was reached for a new classification system for periodontal and periimplant diseases and conditions and was proposed by a group of world experts in 2017. Since then, there have been ongoing debates among periodontists regarding the application of the new classification. This study aims to shed light on the current understanding of the new classification among Egyptian periodontists. Methods: This cross-sectional survey study was performed using an anonymous manually distributed questionnaire in various universities in Egypt. The validated questionnaire included 15 questions - 13 multiple choice questions with a Likert scale and two open ended questions, in addition to demographic data of the participant. Qualitative data were presented as frequencies and percentages, and binary and ordinal logistic regression analyses were performed. Results: The clarity of the new classification was the only significant predictor for satisfaction. An increase in clarity scores was directly associated with an increase in satisfaction scores (odds ratio $=5.521,95 \% \mathrm{Cl}=2.198-8.844$, P-value $=0.001$ ). Only $24.2 \%$ of the participants actually applied the new classification. There was a high approval rate on the introduction of "health on reduced periodontium" and the classification of peri-implant conditions. However, there was a huge dissatisfaction with applying the staging and grading system as well as the omission of aggressive periodontitis. Conclusions: This survey has identified important gaps between theory and practice and bridging these gaps by revising the controversial points would help develop a clearer, simpler system for clinicians to improve patients' oral health.
\end{abstract}

Keywords: Classification; periodontal diseases; periodontitis; peri-implantitis

\section{Introduction}

For many decades, different periodontal classification systems have been proposed with the purpose of grouping diseases into distinct categories based on scientific data. ${ }^{1-}$ ${ }^{3}$ The main goal has always been to reach a correct clinical diagnosis and subsequently apply the most appropriate treatment. Moreover, with the development of each classification system, a cascade of studies was performed to provide a structured framework for better understanding of the etiology and pathogenesis of different periodontal diseases in order to clear any knowledge gaps. This is in addition to encouraging new treatments modalities to evolve which addressed the proposed disease categories. ${ }^{4}$ Hence, a flash back in the history of classification of periodontal diseases is crucial to understanding where we stand today (Figure 1).

The 1999 International Workshop for Classification of Periodontal Disease and Conditions assented to a detailed classification of periodontal conditions. Over 40 gingival diseases were plotted under two main categories: plaque induced and nonplaque induced gingivitis. This is in addition to seven main categories of disease including periodontitis as a manifestation of systemic diseases, chronic periodontitis instead of adult periodontitis, and aggressive periodontitis as a substitute for early onset periodontitis, which was considered the 
umbrella of all former types of periodontitis affecting young patients, namely: juvenile, prepubertal, and rapidly progressive periodontitis. ${ }^{2-6}$

The 2017 periodontal classification aimed to update the 1999 classification. It was developed in the "World Workshop on The Classification of Periodontal and Periimplant Diseases and Conditions" copresented by the American Academy of Periodontology and the European Federation of Periodontology. The most highlighted update was the grouping of the formerly distinguished forms of periodontitis, chronic and aggressive, under a single category using a new staging and grading system for periodontitis. ${ }^{2}$ This is in addition to a new classification for gingival recession substituting the widely used Miller's

Figure 1. Periodontal classification timeline classification. ${ }^{7}$ The workshop also developed a new category to include periimplant health and diseases such as periimplant mucositis and peri-implantitis. ${ }^{8}$

The 1999 classification of periodontal diseases, which had been used for almost two decades, needed to be updated based on new knowledge on pathophysiology and clinical findings of different periodontal diseases. ${ }^{2,4,8}$ Applying new knowledge and a new system is always faced with certain challenges, which include the awareness level, the technical difficulties, the feasibility of application, and the size of the gap between theory and practice. Therefore, this study was designed to assess the level of awareness and knowledge of the new periodontal classification among periodontists.

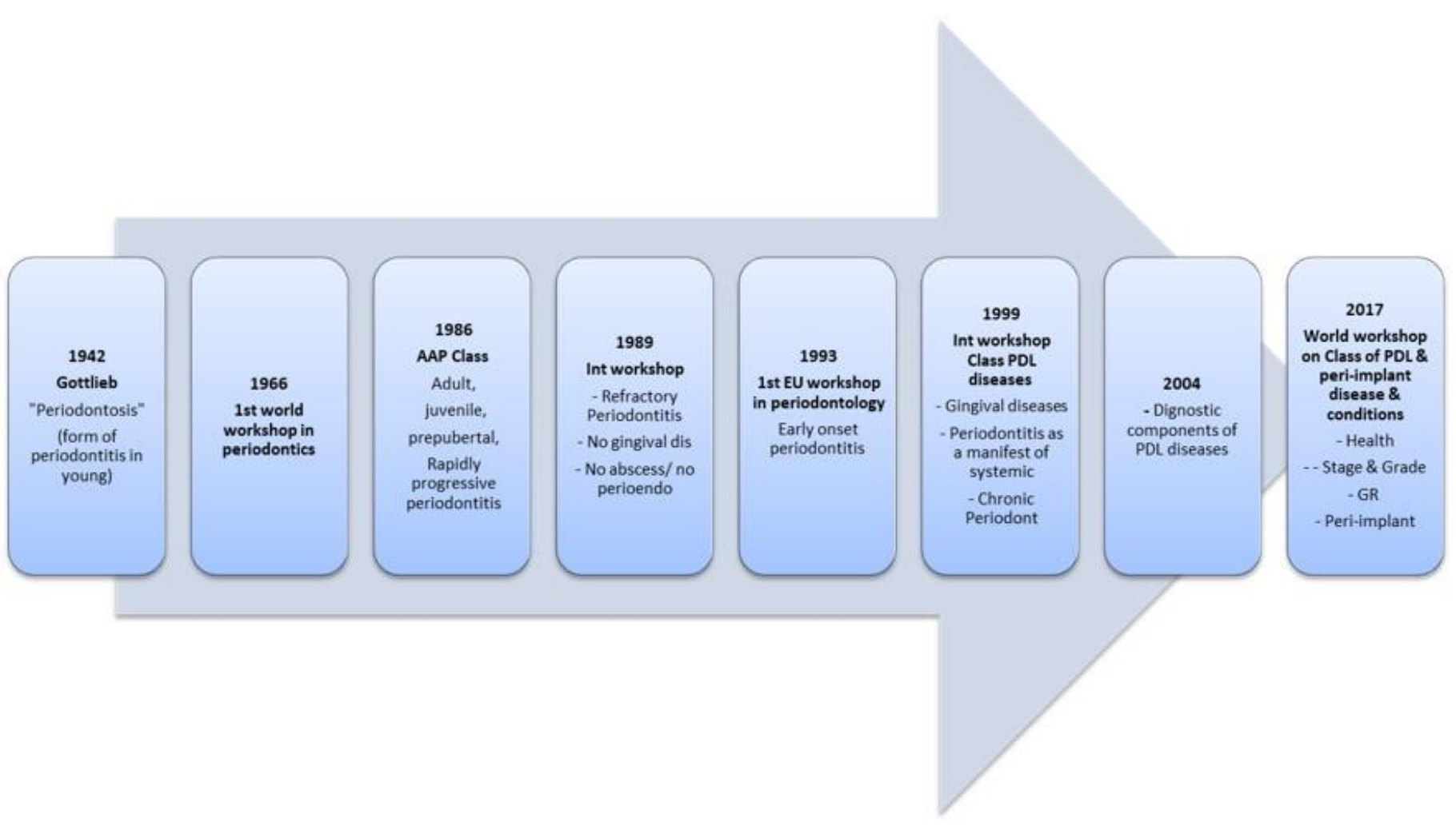

\section{Materials and Methods}

The present study was approved by the Research Ethics Committee of the Faculty of Dentistry of Beni-Suef University (ID \#FDBSUREC/27022019/AM) and was conducted in full accordance with the World Medical Association's Declaration of Helsinki 1975 (revised in 2003). The questionnaire was anonymous with no personal identification data. Completion and submission of the questionnaire was considered an approved informed consent to participate in the study by the Research Ethics Committee.

The questionnaire was designed by the authors and pilot tested on a group of 12 periodontists for validation. Afterwards, adjustments were made to ensure a clear and comprehensive version of the questionnaire. The questionnaire had a cover letter explaining the nature and purpose of the survey and comprised 15 
Figure 2. Questionnaire

\section{Questionnaire}

Administrative data:

- Age Gender

M $\square$

F $\square$

- Position/Degree:

- Years of practice

Flow of patients

per day

- Setting of practice (university/hospital/private practice/other

Have you heard about the new classification for periodontal diseases?

$$
\begin{aligned}
& \square \quad \text { Yes } \\
& \square \quad \text { No }
\end{aligned}
$$

If yes, please answer the following questions by choosing a number where each represents:

$\begin{array}{lllll}\text { 1. Strongly disagree } & 2 \text {. Slightly disagree } & 3 \text {. Neutral } & 4 \text {. Slightly agree } & \mathbf{5} \text {. Strongly agree }\end{array}$

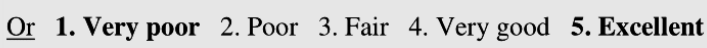

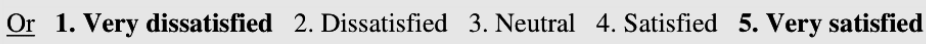

\begin{tabular}{|c|c|c|c|c|c|c|c|}
\hline & & $\underline{1}$ & $\underline{2}$ & $\underline{3}$ & $\underline{4}$ & $\underline{5}$ & $\underline{\mathrm{DK}}$ \\
\hline 1. & How would you rate the clarity of the new classification? & & & & & & \\
\hline 2. & Have you applied the new classification at your clinic? & No & & & & Yes & \\
\hline 3. & $\begin{array}{l}\text { What do you think of adding this item to the new classification "clinical } \\
\text { health on a reduced periodontium?" }\end{array}$ & & & & & & \\
\hline 4. & What is your opinion of the definition of a periodontitis case? & & & & & & \\
\hline 5. & How would you rate the staging and grading process in periodontitis? & & & & & & \\
\hline 6. & $\begin{array}{l}\text { What is your opinion of replacing "aggressive periodontitis" with a higher } \\
\text { stage and grade on a periodontitis scale? }\end{array}$ & & & & & & \\
\hline 7. & $\begin{array}{l}\text { Is the staging and grading of periodontitis applicable in the day to day dental } \\
\text { clinic? }\end{array}$ & & & & & & \\
\hline 8. & $\begin{array}{l}\text { Are the systemic diseases affecting the periodontium (and vice versa) clearly } \\
\text { covered in the new classification? }\end{array}$ & & & & & & \\
\hline 9. & $\begin{array}{l}\text { What is your opinion of replacing Miller's classification of gingival recession } \\
\text { with the new classification of Cairo et al. in addressing mucogingival } \\
\text { conditions? }\end{array}$ & & & & & & \\
\hline 10. & $\begin{array}{l}\text { Is the implant health and disease incorporation into the new classification } \\
\text { useful? }\end{array}$ & & & & & & \\
\hline 11. & $\begin{array}{l}\text { Do you think the prognosis and treatment planning of periodontal cases will } \\
\text { differ in relation to the new classification? }\end{array}$ & & & & & & \\
\hline 12. & $\begin{array}{l}\text { Is the new classification user-friendly for periodontists and general } \\
\text { practitioners regarding their patients flow? }\end{array}$ & & & & & & \\
\hline 13. & $\begin{array}{l}\text { How satisfied or dissatisfied are you with the overall new classification } \\
\text { scheme? }\end{array}$ & & & & & & \\
\hline
\end{tabular}

Or (DK) Don't know:

14. What are the advantages of the new classification?

15. What are the limitations of the new classification?

Other comments: 
questions addressing the fundamental modifications of the new classification. The first six statements of the questionnaire were descriptive in nature addressing the participant's demographics, and the seventh was a question on whether or not the participant was aware of the new periodontal classification. Only those who were aware of it were asked to proceed to 13 multiple choice questions using the Likert scale, ranging from "strongly disagree" to "strongly agree" or from "excellent" to "poor", in addition to an "I don't know" option. ${ }^{9}$ There were also three open ended questions for further comment at the end of the questionnaire (Figure 2).

All questionnaires were manually distributed to periodontists and postgraduate students enrolled in master's and $\mathrm{PhD}$ programs at the Periodontology Department of a number of public and private universities in Egypt, namely Cairo University, Ain Shams University, Al-Azhar University, BeniSuef University, Misr International University, University of Modern Sciences and Arts, Modern University for Technology and Information, and Ahram Canadian University. The responses were collected over a period of eight weeks.

Numerical data were presented as mean and standard deviation (SD) values. Qualitative data were presented as frequencies and percentages. Binary logistic regression analysis was performed to determine significant predictors for the new classification application. Ordinal regression analysis was performed to determine significant predictors of satisfaction with the new classification. The significance level was set at $P \leq 0.05$. Statistical analysis was performed using computer software. ${ }^{a}$

\section{Results}

\section{Response Rate and Piloting}

The questionnaire was distributed to 12 periodontists for validation and whose responses were not included within the study results. It was subsequently distributed to 188 participants, 91 of whom responded, giving a response rate of $48.4 \%$. (Figure 3 ).

Figure 3. Questionnaire distribution

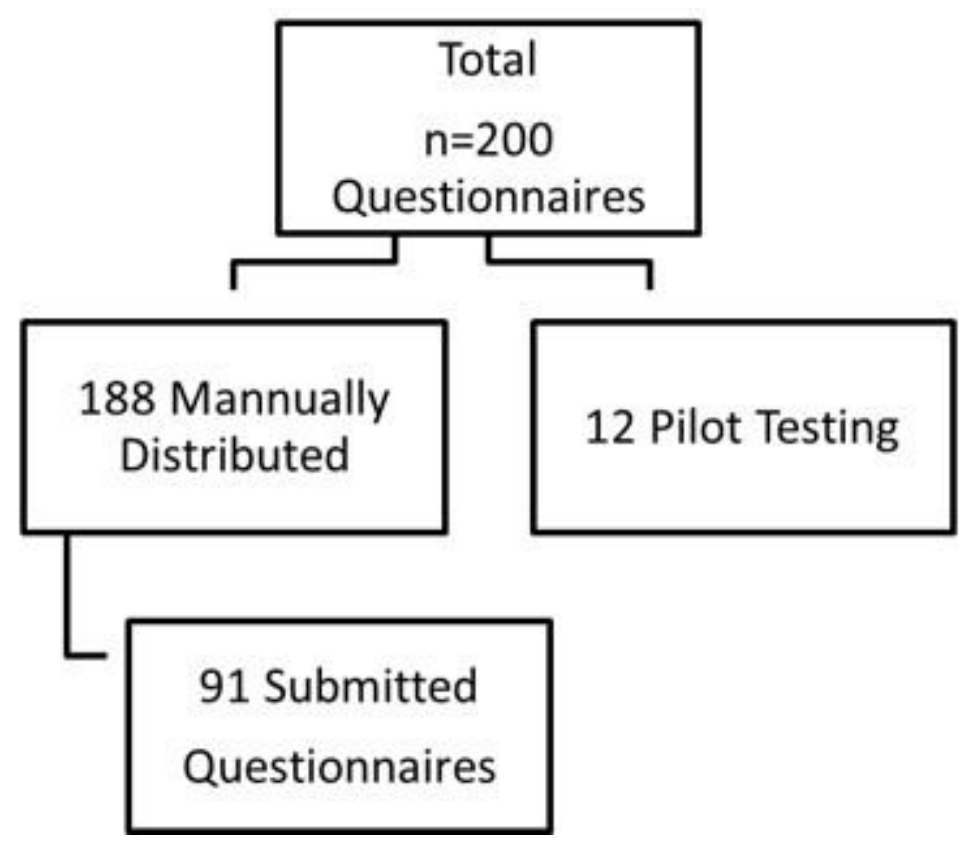

\section{Demographics}

The present study was conducted on 91 periodontists, 52 of whom were females
(57.1\%) and 39 males (42.9\%). The mean \pm standard deviation values for age were 31.2 \pm 5.2 years with a minimum of 25 and a maximum of 52 years, and a $95 \%$

\footnotetext{
a IBM® Statistical Package for Social Sciences (SPSS®) for Windows (Version 23.0. Armonk, NY: IBM Corp.)
} 
confidence interval $(\mathrm{Cl})(30.1-32.3)$ years. As regards the educational level, $40.7 \%$ were master's degree students, $31.9 \%$ were master's degree holders, $7.7 \%$ were $\mathrm{PhD}$ students, $12.1 \%$ were $\mathrm{PhD}$ holders, and $6.6 \%$ did not report their educational level. Regarding employment, $36.3 \%$ were university staff members only, $7.7 \%$ had a private dental practice only, $4.4 \%$ worked at a hospital, $1.1 \%$ worked at the National Research Center, 5.5\% had hospital and private work, $25.3 \%$ had university and private work, and $1.1 \%$ had university and hospital work.

\section{Questions Regarding the New Classification of Periodontal Disease}

All participants had knowledge about the new classification of periodontal disease. However, only $24.2 \%$ of participants applied it in their clinical practice. The clarity of the new classification had been viewed as very poor/poor by $34 \%$ of participants while it was considered very good/excellent by $29.7 \%$ of the participating dentists (Table 1).

About $55 \%$ of participants agreed on the addition of "clinical health on a reduced periodontium" item to the new classification. Defining a patient as a periodontitis case was agreed/strongly agreed upon by $33 \%$ of participants and opposed by $26.4 \%$ of participants. The staging and grading classification for periodontitis was considered very good/excellent by $40.7 \%$ of participants and considered very poor/poor by $27.5 \%$ of them. Replacing "aggressive periodontitis" with a higher grading on a periodontitis scale was strongly/slightly disagreed upon by $47.3 \%$ of participants, while $30.8 \%$ slightly/strongly agreed upon this replacement. The applicability of staging and grading of periodontitis in day to day dental practice was strongly disagreed upon by $14.3 \%$ of participants, while $7.7 \%$ strongly agreed on its applicability (Table 1).

The clarity of covering systemic diseases affecting the periodontium in the new classification was slightly/strongly agreed upon by $35.2 \%$ of participants while $26.4 \%$ strongly/slightly disagreed upon it. Replacing Miller's classification of gingival recession with a new classification addressing mucogingival conditions was slightly/strongly agreed upon by $38.5 \%$ of participants, while $19.8 \%$ strongly/slightly disagreed upon this replacement (Table 1).

The usefulness of implant health and disease incorporation into the new classification was disagreed upon. About $36.3 \%$ of participants slightly/strongly agreed that the prognosis and treatment planning of periodontal cases will differ in relation to the new classification while $33 \%$ strongly/slightly disagreed with that assumption (Table 1).

Table 1. Frequencies ( $n$ ) and percentages (\%) of responses to questions about the new classification for periodontal diseases

\begin{tabular}{|l|c|c|}
\hline \multicolumn{1}{|c|}{ Question } & n & $\%$ \\
\hline 1) Clarity of the new classification: & & \\
\hline a. Very poor & $5 / 91$ & 12 \\
\hline b. Poor & $20 / 91$ & 22 \\
\hline c. Fair & $35 / 91$ & 38.5 \\
\hline d. Very good & $17 / 91$ & 18.7 \\
\hline e. Excellent & $10 / 91$ & 11 \\
\hline f. Don't know & $4 / 91$ & 4.4 \\
\hline 2) Have you applied the new classification at your clinic? & $22 / 91$ & 24.2 \\
\hline a. Yes & $59 / 91$ & 64.8 \\
\hline b. No & $10 / 91$ & 11 \\
\hline c. Don't know/No answer & & \\
\hline 3) What do you think of adding this item to the new classification: "clinical & & 12 \\
\hline health on a reduced periodontium?" & $5 / 91$ & \\
\hline a. Strongly disagree & \\
\hline
\end{tabular}




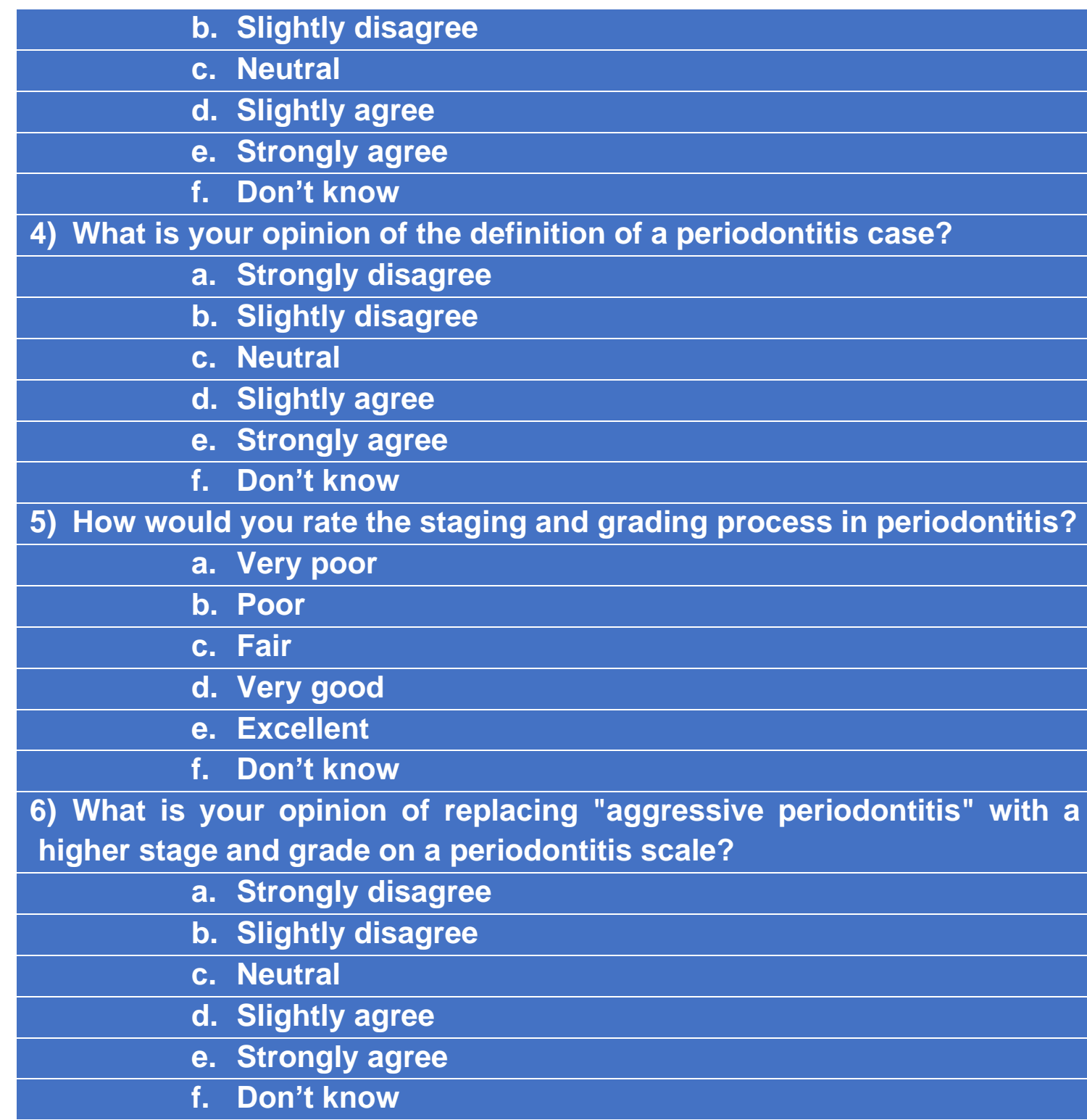

$13 / 91 \quad 14.3$

$18 / 91 \quad 19.8$

$19 / 91 \quad 20.9$

$31 / 91 \quad 34.1$

$5 / 91 \quad 5.5$

\begin{tabular}{l|l}
$9 / 91$ & 9.9
\end{tabular}

$15 / 91 \quad 16.5$

$30 / 91 \quad 33$

\begin{tabular}{l|l}
$14 / 91$ & 15.4 \\
\hline
\end{tabular}

$16 / 91 \quad 17.6$

\begin{tabular}{|l|l|}
\hline $7 / 91$ & 7.7
\end{tabular}

\begin{tabular}{l|l|}
\hline $8 / 91$ & 8.8 \\
\hline
\end{tabular}

$\begin{array}{ll}17 / 91 & 18.7\end{array}$

\begin{tabular}{ll|}
\hline $24 / 91$ & 26.4
\end{tabular}

$21 / 91 \quad 23.1$

$16 / 91 \quad 17.6$

$5 / 91 \quad 5.5$

7) Is the staging and grading of periodontitis applicable in the day to day dental clinic?
a. Strongly disagree
b. Slightly disagree
c. Neutral
d. Slightly agree
e. Strongly agree
f. Don't know

$25 / 91 \quad 27.5$

$18 / 91 \quad 19.8$

$15 / 91 \quad 16.5$

$18 / 91 \quad 19.8$

$10 / 91 \quad 11$

$5 / 91 \quad 5.5$

8) Are the systemic diseases affecting the periodontium (and vice versa) clearly covered in the new classification?

\begin{tabular}{|l|c|c|}
\hline a. Strongly disagree & $7 / 91$ & 7.7 \\
\hline b. Slightly disagree & $17 / 91$ & 18.7 \\
\hline c. Neutral & $27 / 91$ & 29.7 \\
\hline d. Slightly agree & $15 / 91$ & 16.5 \\
\hline e. Strongly agree & $17 / 91$ & 18.7 \\
\hline f. Don't know & $8 / 91$ & 8.8 \\
\hline
\end{tabular}

9) What is your opinion of replacing Miller's classification of gingival recession with the new classification of Cairo et al. in addressing mucogingival conditions?
a. Strongly disagree
$4 / 91 \quad 4.4$
b. Slightly disagree
$14 / 91 \quad 15.4$
c. Neutral
d. Slightly agree
e. Strongly agree
f. Don't know

\begin{tabular}{|c|c|}
\hline $13 / 91$ & 14.3 \\
\hline $20 / 91$ & 22 \\
\hline $25 / 91$ & 27.5 \\
\hline $21 / 91$ & 23.1 \\
\hline $7 / 91$ & 7.7 \\
\hline $5 / 91$ & 5.5 \\
\hline & \\
\hline $7 / 91$ & 7.7 \\
\hline $17 / 91$ & 18.7 \\
\hline $27 / 91$ & 29.7 \\
\hline $15 / 91$ & 16.5 \\
\hline $17 / 91$ & 18.7 \\
\hline $8 / 91$ & 8.8 \\
\hline & \\
& \\
\hline & \\
\hline $4 / 91$ & 4.4 \\
\hline $14 / 91$ & 15.4 \\
\hline $23 / 91$ & 25.3 \\
\hline $12 / 91$ & 13.2 \\
\hline $23 / 91$ & 25.3 \\
\hline $15 / 91$ & 16.5 \\
\hline
\end{tabular}




\begin{tabular}{|c|c|c|}
\hline \multicolumn{3}{|l|}{$\begin{array}{l}\text { 10) Is the implant health and disease incorporation into the new } \\
\text { classification useful? }\end{array}$} \\
\hline a. Strongly disagree & $6 / 91$ & 6.6 \\
\hline b. Slightly disagree & $10 / 91$ & 11 \\
\hline c. Neutral & $21 / 91$ & 23.1 \\
\hline d. Slightly agree & $19 / 91$ & 20.9 \\
\hline e. Strongly agree & 19/91 & 20.9 \\
\hline f. Don't know & $16 / 91$ & 17.6 \\
\hline \multicolumn{3}{|l|}{$\begin{array}{l}\text { 11) Do you think the prognosis and treatment planning of periodontal } \\
\text { cases will differ in relation to the new classification? }\end{array}$} \\
\hline a. Strongly disagree & $11 / 91$ & 12.1 \\
\hline b. Slightly disagree & 19/91 & 20.9 \\
\hline c. Neutral & 20/91 & 22 \\
\hline d. Slightly agree & $19 / 91$ & 20.9 \\
\hline e. Strongly agree & $14 / 91$ & 15.4 \\
\hline f. Don't know & $8 / 91$ & 8.8 \\
\hline \multicolumn{3}{|l|}{$\begin{array}{l}\text { 12) Is the new classification user-friendly for periodontists and general } \\
\text { practitioners regarding their patients flow? }\end{array}$} \\
\hline a. Strongly disagree & $25 / 91$ & 27.5 \\
\hline b. Slightly disagree & 22/91 & 24.2 \\
\hline c. Neutral & $18 / 91$ & 19.8 \\
\hline d. Slightly agree & $12 / 91$ & 13.2 \\
\hline e. Strongly agree & $4 / 91$ & 4.4 \\
\hline f. Don't know & $10 / 91$ & 11 \\
\hline \multicolumn{3}{|l|}{$\begin{array}{l}\text { 13) How satisfied or dissatisfied are you with the overall new } \\
\text { classification scheme? }\end{array}$} \\
\hline a. Very dissatisfied & $10 / 91$ & 11 \\
\hline b. Dissatisfied & $21 / 91$ & 23.1 \\
\hline c. Neutral & $24 / 91$ & 26.4 \\
\hline d. Satisfied & 18/91 & 19.8 \\
\hline e. Very satisfied & $8 / 91$ & 8.8 \\
\hline f. Don't know & $10 / 91$ & 11 \\
\hline
\end{tabular}

Approximately half of the participants $(51.7 \%)$ strongly/slightly disagreed that the new classification is user-friendly for both periodontists and general practitioners in terms of patient management, in comparison to $17.6 \%$ of participants who considered it user-friendly. Regarding overall satisfaction with the new classification, $34.1 \%$ of participants were dissatisfied/strongly dissatisfied with the new classification, $28.6 \%$ were satisfied/strongly satisfied, $26.4 \%$ were neutral, and $11 \%$ did not know (Figure 4).

\section{Significant Predictors of the New Classification Application}

A binary logistic regression model was constructed using application of the new classification (yes/no) as the dependent variable, while age, gender, degree, setting, and clarity of the new classification were the independent variables. None of the independent variables were found to be statistically significant predictors for applying or not applying the new classification.

\section{Significant Predictors of Satisfaction with the New Classification}

An ordinal regression model was constructed using satisfaction with the new classification (strongly dissatisfied, dissatisfied, neutral, satisfied, strongly satisfied, do not know) as the dependent variable, while age, gender, degree, setting, clarity, and application of the new classification were the independent variables. The results showed that clarity of 
the new classification was the only significant predictor for satisfaction with the new classification. An increase in clarity scores was directly associated with an increase in satisfaction scores (odds ratio $=$
$5.521,95 \% \mathrm{Cl}=2.198-8.844, \mathrm{P}$-value $=$ $0.001)$. An increase of one clarity score (e.g. from very poor to poor) is associated with a 5.5 -fold increase in satisfaction scores.

Figure 4. Pie chart representing overall satisfaction with the new classification for periodontal diseases among the study participants

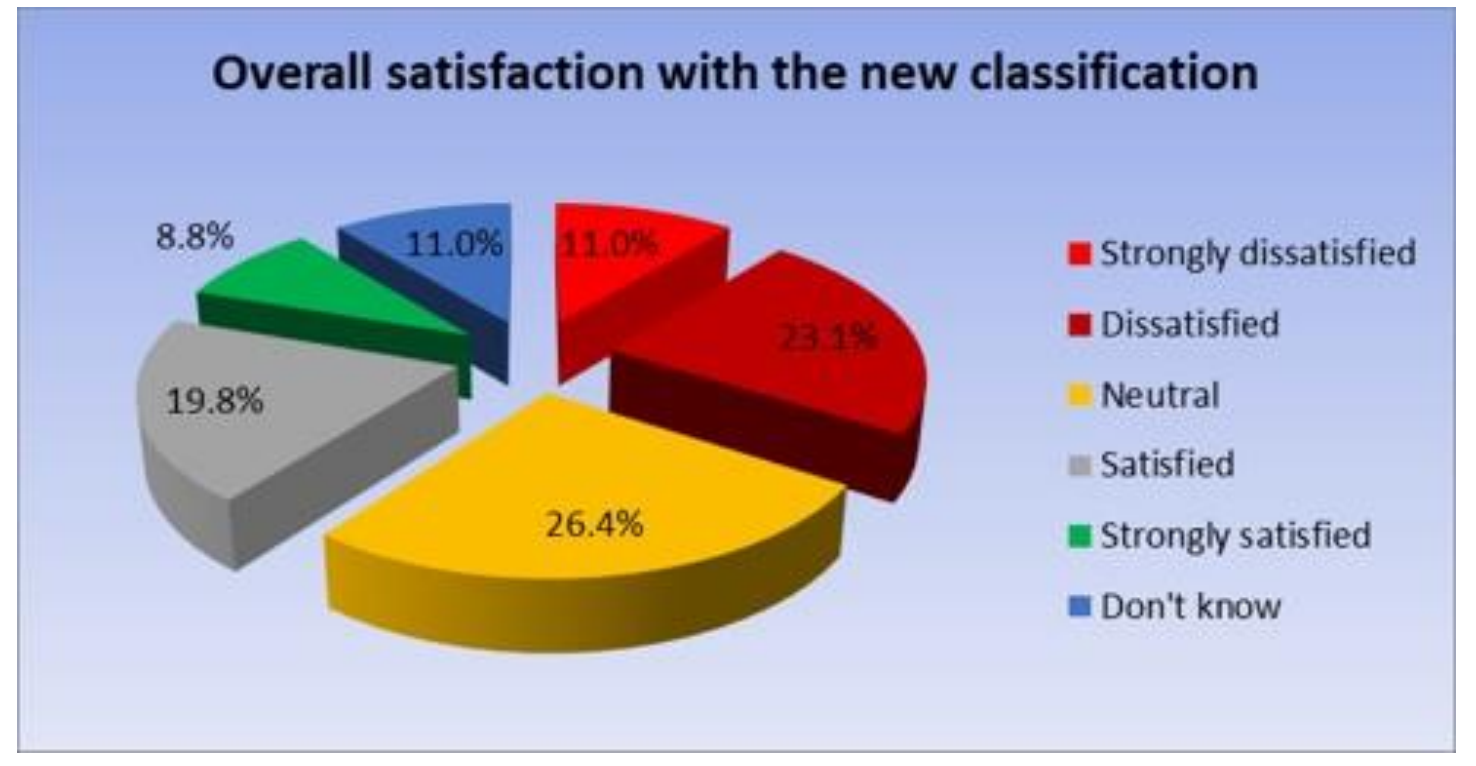

\section{Discussion}

Periodontitis is a multifactorial inflammatory disease, that represents a major worldwide problem due to its high prevalence and its impact on patients' quality of life. Therefore, different classifications have been continuously proposed over the past decades to help reach a correct diagnosis. ${ }^{1,2,8}$ With the recent understanding of periodontal disease pathogenesis and bacterial etiology as well as peri-implant diseases and conditions, a new classification for periodontal diseases and conditions was proposed in the "2017 World Workshop on the Classification Periodontal and Periimplant Diseases and Conditions." The new classification was guided by recent research and robust scientific evidence, but whenever faced with a lack of sufficient data, lower level evidence and expert opinion were inevitable. ${ }^{8}$

In this regard, our survey aimed to assess awareness and clinical application of the new classification among periodontists in different academic institutes and clinical practices. To the best of our knowledge, this is the first report in literature addressing this topic. The questionnaire was distributed to
188 dentists and was completed by only 91 , giving a response rate of $48.4 \%$. This might be due to a lack of motivation, a busy academic life making it difficult to complete volunteer tasks, and perhaps also a lack of clinical application of the new classification by many periodontists.

In an attempt to probe any confounders that might have affected the awareness level of dental practitioners, the authors investigated age, sex, academic degree, years of clinical experience, and affiliation of the participants. ${ }^{9}$ However, all were insignificant predictors for the application of the new classification. This can be explained by the academic background of all participants, which allows exposure to any recent updates in the field.

All participants had heard about the new classification in detail. However, only $24 \%$ of them applied it. This could be attributed to the initial resistance to change if the question about clarity was not raised. However, there was a relatively high negative response of $34 \%$ to the question addressing the clarity of the new classification. 
Clinical health on a reduced periodontium was one of the newly added definitions, which was agreed upon by $55 \%$ of participants, as it clarifies the idea of having a stable periodontium with no active disease or any signs of inflammation, which was previously problematic as to whether categorization should be under health or disease. ${ }^{10}$ Such a distinction was crucial to differentiate between the need for maintenance of successfully treated patients and the comprehensive treatment required for those with active periodontitis. ${ }^{3,8}$

Despite the high support of the idea of "clinical health on a reduced periodontium," the definition of a periodontitis case did not gain similar approval, where only $33 \%$ of participants approved. Our results reflect that there might be some difficulty in understanding the significance of using different values for clinical attachment loss (CAL) between proximal and buccal surfaces, as well as a $3 \mathrm{~mm}$ buccal pocket with CAL being a necessity for case definition, according to the new classification. ${ }^{11,12}$

Although $40.7 \%$ of participants rated "staging and grading" as an excellent/very good addition to the diagnosis of periodontitis, only $7.7 \%$ strongly agreed on clinically implementing its use. This might be attributed to the fact that such a timeconsuming method of diagnosis is unlikely to be applied in institutions receiving mass numbers of patients. For example, the outpatient clinic of the Faculty of Oral and Dental Medicine at Cairo University may receive approximately 1,000 patients per day. This is also strengthened by the outcome of the question as to whether the new classification is user friendly or not, where $57.7 \%$ felt that it was not user friendly. Several participants found the "staging and grading" system too complicated to be used in clinical practice, and even more complicated for general practitioners. Furthermore, the possible need for several diagnostic aids besides clinical and radiographic examination, such as highsensitivity C-reactive protein (hs-CRP), might not be feasible with lack of medical insurance and low socioeconomic standards. This is of course in addition to their concern about the difficulty in explaining the condition to patients taking into consideration the challenge that might arise at using such phrases as "used only in case of cancer" for non-cancer patients.

Replacing aggressive periodontitis with a grading system was disagreed upon by almost half of the participants, in addition to the $22 \%$ who were not sure about its value. This raises a crucial need for further investigation in this regard. One notion adopted against the term "aggressive periodontitis" was based on the impossible accurate estimation of "rapid" progression of periodontal disease. The first claim was the inability to determine the onset of destruction without former clinical records and radiographs, and the possible occurrence of both aggressive and chronic forms of the disease at a young age. Moreover, investigating possible familial tendency is unreliable due to the possibility of undiagnosed patients or unclear reasons for tooth loss. Another claim was the inconsistency in data regarding the amounts of deposits and the severity of destruction. Hence, it was concluded that diagnosing aggressive periodontitis patients was based on a subjective interpretation of cases. ${ }^{4}$ Although the fundamental criticism of the term "aggressive periodontitis" is based on the lack of objective criteria to determine the rate of disease progression, the new grading system of periodontitis is classified into grades $\mathrm{A}, \mathrm{B}$, and $\mathrm{C}$ reflecting slow, moderate, and rapid rates of progression respectively. ${ }^{12}$

Moreover, the current insufficient pathophysiological distinction between aggressive and chronic periodontitis does not undermine the clear clinical distinction and unique phenotype based on rate of progression, age of onset, distribution, clinical presentation, and response to treatment, which is not based solely on severity. The argument that both aggressive and chronic periodontitis both have a common end result, and therefore can be considered as a single disease, counts as an invalidation to the whole periodontal classification system because it is true for all types of periodontitis; all forms of the 
disease can end in tooth loss if left untreated. ${ }^{13}$

Despite the possible overlap of certain cases between both chronic and aggressive forms of periodontitis, many participants objected to totally omitting "aggressive periodontitis" and losing the opportunity to identify its early manifestations. Instead, they suggested adding another category for borderline cases and going for further larger scale studies in this regard, in order to provide reliable evidence rather than discarding the insufficient data. Given the fact that this form of periodontitis is common in the Middle East and Africa, defining aggressive periodontitis as an orphan disease based on its prevalence in the United States does not reflect its actual load. ${ }^{13}$

The suggestion that socioeconomic factors might be related to disease susceptibility is true for almost any disease where a genotype needs certain environmental factors to be expressed, as is the case with diabetes mellitus type II for example. ${ }^{13}$ Identifying those environmental factors can help in the development of preventive programs for such diseases by targeting and controlling specific environmental risk factors. A question was also raised by the participants regarding the impact of each grade on the treatment plan. In other words, would the treatment of grades $\mathrm{B}$ and $\mathrm{C}$ periodontitis require antibiotics as was the case with aggressive periodontitis?

In the new classification, systemic disorders fall under three main categories; the first includes those having a major impact on the loss of periodontal tissue by influencing periodontal inflammation, which is further subdivided into genetic conditions and acquired immunodeficiency and inflammatory diseases; the second includes systemic disorders that influence the pathogenesis of periodontal diseases, and third are the systemic disorders that can result in loss of periodontal tissue independent of periodontitis. ${ }^{14}$ In the present study, the assessment of the clarity of systemic diseases affecting the periodontium was debatable; approximately
$25 \%$ of participants disagreed, about $35 \%$ agreed, and $40 \%$ were neutral or did not know. This might be explained by the fact that the new classification offers a detailed categorization of disorders and conditions based on underlying mechanisms which is essential at an academic level, but it might need a bit of zoom out to offer a clearer understanding for clinical application. Moreover, such a categorization does not take into consideration the fact that periodontal inflammation and the pathogenesis of periodontal disease overlap in certain conditions. Being an inflammatory disease, any condition that affects the pathogenesis of periodontal disease will definitely have an impact on inflammation. Furthermore, the new classification provides a detailed discussion on the effect of systemic conditions on the periodontium and completely ignores periodontal disease as a risk for different systemic conditions such as cardiovascular diseases and pregnancy, despite the presence of high evidence in that regard. ${ }^{15-17}$

A new classification of gingival biotype and gingival recession was also proposed taking into consideration recession type, recession depth, gingival thickness, keratinized tissue width, and the cementoenamel junction (CEJ), thus, overcoming the limitations of former classifications. ${ }^{18,19}$ Replacing the widely used Miller's classification with a new classification received wide approval, where $38.5 \%$ approved in comparison to $19.8 \%$ who disapproved. This may be due to the appeal of having such a comprehensive diagnostic approach of the dento-gingival unit, which involves all the possible factors that might impact the outcome when attempting treatment of gingival recession.

The addition of implant health and disease to the new classification gained the approval of almost half of the participants. This can be explained by the rising need to make a distinction between peri-implant health and peri-implantitis and peri-implant mucositis based on objective criteria to help accurately diagnose and treat various implant related diseases and conditions. ${ }^{20-24}$ 
The response of participants was controversial regarding the impact of the new classification on the prognosis and treatment of periodontal diseases and conditions. Thirty-six and three tenths percent of periodontists agreed that the prognosis and treatment of cases will differ under the umbrella of the new classification, $33 \%$ disagreed, while $30 \%$ were neutral or did not know. This might reflect the subjective interpretation of several aspects of the new classification, which may need amendments to clear the gray areas that might adversely affect the patient. For instance, the prescription of antibiotics for certain categories which had an established evidence of positive impact on the treatment outcome, remain unclear under the umbrella of the new classification. ${ }^{25,26}$

The clarity of the new classification was the only significant predictor for the overall satisfaction with the classification, where $34.1 \%$ were dissatisfied, $28.6 \%$ were satisfied, $26.4 \%$ were neutral, and $11 \%$ did not know. An increase of one clarity score was associated with a 5.5-fold increase in the satisfaction score. Our findings are generally indicative of certain inadequacies in the new classification and a gap between theory and practice due to a lack of clarity of certain aspects of the classification as perceived by periodontists with an academic background in Egypt.

One of the limitations of the present study is the fact that all participants in the survey were Egyptian, and all had an academic background with continuous access to updates unlike general practitioners. Another limitation is the relatively small sample size, and the need for further large-scale studies with participants from diverse backgrounds. The present study also has the inherent weakness of survey studies using questionnaires in which some responses are always lost.

Our study sheds light on some important questions that need to be addressed in the near future including whether all aspects of the new classification system are applicable in developing countries and megacities receiving a mass number of patients, and whether it is more rational to further explore aggressive periodontitis using large scale studies in countries with high prevalence before its omission as a distinct disease entity.

The goal behind the classification of periodontal diseases and conditions has always been to provide a framework to help develop effective treatments to such a complex group of conditions. Ever since the introduction of the classification systems, there have been inadequacies and inconsistencies. ${ }^{2}$ Despite the huge effort exerted by eminent world experts and the consensus reached, further revisions to the new classification are needed to facilitate its application in order to confer the greatest benefit to the patient.

\section{Acknowledgments:}

The authors acknowledge the contribution of Dr. Khaled Kerra (biostatistician) for performing the statistical analysis.

\section{References}

1. Nevins M, Becker W, Kornman K. The American Academy of Periodontology. Consensus Report, Discussion Section I. Proceedings of the World Workshop in Clinical Periodontics. Periodontal Diagnosis and Diagnostic Aids. Chicago. The American Academy of Periodontology. 1989; 1/23-32.

2. Armitage GC. Development of a Classification System for Periodontal Diseases and Conditions. Ann Periodontol. 1999 Dec; 4(1):1-6. https://doi.org/10.1902/annals.1999.4.1. 1

3. Armitage GC. Periodontal diagnoses and classification of periodontal diseases. Periodontol 2000. 2004 Feb; 34(1):9-21. https://doi.org/10.1046/j.09066713.2002.003421.x

4. Van der Velden U. What exactly distinguishes aggressive from chronic periodontitis: is it mainly a difference in the degree of bacterial invasiveness? Periodontol 2000. 2017 Oct; 75(1):24-44. https://doi.org/10.1111/prd.12202

5. Lindhe J, Ranney R, Lamster I, et al. Consensus Report: Chronic Periodontitis. Ann Periodontol. Dec 
1999;

4(1):38

https://doi.org/10.1902/annals.1999.4.1.

38

6. Lang N, Bartold PM, Cullinan M, et al. Consensus Report: Aggressive Periodontitis. Ann Periodontol. Dec 1999; 4(1):53. https://doi.org/10.1902/annals.1999.4.1. 53

7. Miller PD Jr. A Classification of Marginal Tissue Recession. Int J Periodontics Restorative Dent. 1985; 5(2):8-13.

8. Caton JG, Armitage G, Berglundh T, et al. A new classification scheme for periodontal and peri-implant diseases and conditions - Introduction and key changes from the 1999 classification. $J$ Clin Periodontol. 2018 Jun; 45 Suppl 20:S1-S8.

https://doi.org/10.1111/jcpe.12935

9. Alrashdan MS, Darwazeh AMG, Hassona $\mathrm{Y}$, Bader DH, Khader YS. Awareness of oral medicine among medical practitioners, evidence of the unbridged interdisciplinary gap. J Eval Clin Pract. 2019 Feb; 25(1):142-147. https://doi.org/10.1111/jep.13029

10. Lang NP, Bartold PM. Periodontal health. J Periodontol. 2018 Jun; 89 Suppl 1:S9S16. https://doi.org/10.1002/JPER.160517

11. Papapanou PN, Sanz M, Buduneli N, et al. Periodontitis: Consensus report of workgroup 2 of the 2017 World Workshop on the Classification of Periodontal and Peri-Implant Diseases and Conditions. J Periodontol. 2018 Jun; 89 Suppl 1:S173-S182. https://doi.org/10.1002/JPER.17-0721

12. Tonetti MS, Greenwell H, Kornman KS. Staging and grading of periodontitis: Framework and proposal of a new classification and case definition. $J$ Periodontol. 2018 Jun; 89 Suppl 1:S159S172. https://doi.org/10.1002/JPER.180006

13. Fine DH, Patil AG, Loos BG. Classification and diagnosis of aggressive periodontitis. J Periodontol. 2018 Jun; 89 Suppl 1:S103-S119. https://doi.org/10.1002/JPER.16-0712
14. Albandar JM, Susin C, Hughes FJ. Manifestations of systemic diseases and conditions that affect the periodontal attachment apparatus: Case definitions and diagnostic considerations. $J$ Periodontol. 2018 Jun; 89 Suppl 1:S183S203. https://doi.org/10.1002/JPER.160480

15. Mustapha IZ, Debrey S, Oladubu M, Ugarte R : Markers of Systemic Bacterial Exposure in Periodontal Disease and Cardiovascular Disease Risk: A Systematic Review and Meta-Analysis. J Periodontol. 2007 Dec; 78(12):2289-302. https://doi.org/10.1902/jop.2007.070140

16. Lafon A, Pereira B, Dufour $\mathrm{T}$, et al. Periodontal disease and stroke: a metaanalysis of cohort studies. Eur $J$ Neurol. 2014 Sep; 21(9):1155-61, e-667. https://doi.org/10.1111/ene.12415

17. Ide M, Papapanou PN. Epidemiology of association between maternal periodontal disease and adverse pregnancy outcomes

systematic review. J Periodontol. 2013 Apr; $\quad 84(4 \quad$ Suppl):S181-94. https://doi.org/10.1902/jop.2013.134009

18. Cairo F, Nieri M, Cincinelli S, Mervelt J, Pagliaro U. The interproximal clinical attachment level to classify gingival recessions and predict root coverage outcomes: an explorative and reliability study. J Clin Periodontol. 2011 Jul; 38(7):661-6.

https://doi.org/10.1111/j.1600-

051X.2011.01732.x

19. Cortellini P, Bissada NF. Mucogingival conditions in the natural dentition: Narrative review, case definitions, and diagnostic considerations. J Clin Periodontol. 2018 Jun; 89 Suppl 1:S204S213. https://doi.org/10.1002/JPER.160671

20. Araujo MG, Lindhe J. Peri-implant health. J Periodontol. 2018 Jun; 89 Suppl 1:S249-S256.

https://doi.org/10.1002/JPER.16-0424

21. Heitz-Mayfield LJA, Salvi GE. Periimplant mucositis. J Periodontol. 2018 Jun; 89 Suppl 1: S257-S266. https://doi.org/10.1002/JPER.16-0488

22. Schwarz F, Derks J, Monje A, Wang H-L. Peri-implantitis. J Periodontol. 2018 Jun; 
$89 \quad$ Suppl 1:2S67-S290. https://doi.org/10.1002/JPER.16-0350

23. Hämmerle CHF, Tarnow D. The etiology of hard- and soft-tissue deficiencies at dental implants: A narrative review. J Clin Periodontol. 2018 Jun; 45 Suppl 20:S267-S277. https://doi.org/10.1111/jcpe.12955

24. Renvert S, Persson GR, Pirih FQ, Camargo PM. Peri-implant health, periimplant mucositis, and peri-implantitis: Case definitions and diagnostic considerations. J Clin Periodontol. 2018 Jun; 45 Suppl 20:S278-S285. https://doi.org/10.1111/jcpe.12956

25. Mestnik MJ, Feres M, Figueiredo LC, et al. The effects of adjunctive metronidazole plus amoxicillin in the treatment of generalized aggressive periodontitis: a 1-year double-blinded, placebo-controlled, randomized clinical trial. J Clin Periodontol. 2012 Oct; 39(10): 955-61. https://doi.org/10.1111/j.1600051X.2012.01932.X

26. Cifcibasi E, Kantarci A, Badur S, Issever $\mathrm{H}$, Cintan S. Impact of metronidazole and amoxicillin combination on matrix metalloproteinases-1 and tissue inhibitors of matrix metalloproteinases balance in generalized aggressive periodontitis. Eur J Dent. 2015 Jan-Mar; 9(1):53-59. https://doi.org/10.4103/13057456.149642

Conflicts of interest: The authors declared no conflicts of interest related to this work.

\section{Corresponding author:}

Dr. Maha Abdelkawy

Lecturer, Department of Oral Medicine and Periodontology

Faculty of Dentistry

Beni-Suef University Industrial Education Campus, East of the Nile

Beni-Suef,Egypt

E-mail: maha abdelkawy@dent.bsu.edu.eg Phone: +20 1005276754

This is an open access article distributed under the Creative Commons AttributionNoncommercial-NoDerivatives 4.0 International (CC BY-NC-ND 4.0) License. 